\title{
Discharge of Hydrothermal Fluids on Ridge Flanks: Recent Discoveries and Future Potential
}

\author{
CHARLES GEOFFREY WHEAT ${ }^{1}$, BETH ORCUTT ${ }^{2}$ AND \\ JAMES MCMANUS ${ }^{2}$ \\ ${ }^{1}$ University of Alaska Fairbanks \\ ${ }^{2}$ Bigelow Laboratory for Ocean Sciences \\ Presenting Author: wheat@mbari.org
}

Most ( $80 \%)$ of the Ocean's advective heat loss occurs on ridge flanks and is driven by conductive heat loss from the mantle and focused through heterogeneous seafloor topography and sediment cover. Although there are likely millions of sites where such crustal formation fluids discharge, only a few sites have been sampled, spanning a temperature range of $10^{\circ} \mathrm{C}-64^{\circ} \mathrm{C}$ in upper basaltic crust. Additional crustal fluids have been collected using borehole observatories that penetrate into the upper basaltic crust. Combined these fluids provide a snapshot of current conditions, compared to the rock record in the upper basaltic crust, which integrates reaction conditions. These fluids also highlight complex hydrologic systems and a range of reaction sources (sediment and basalt) and types (abiotic and biotic).

Dorado Outcrop (Pacific), North Pond (Atlantic), and Davidson Seamount (Pacific) support underlying low temperature $\left(<15^{\circ} \mathrm{C}\right)$ and oxic hydrothermal system. Such systems represent much of the fluid discharge from ridge flanks, in contrast to the more altered, anoxic and warm $\left(64^{\circ} \mathrm{C}\right)$ fluids that discharge from the eastern flank of the Juan de Fuca Ridge. This range of hydrothermal processes represents the "cycle of life" for ridge flank hydrothermal systems that follow an evolutionary path with increasing age and sediment thickness from cool $\left(<15^{\circ} \mathrm{C}\right)$ to warm $\left(>30^{\circ} \mathrm{C}\right)$ discharge before discharge ceases, yet convection will continue within the crust. To place some of the observed trends in the context of water-basalt reactions, we will present data from the first two years of a fiveyear water-rock experiment. This experiment included containers that were filled with unfiltered seawater and glassy basalt and others that were filled only with unfiltered seawater at three temperatures $\left(2,20\right.$, and $\left.65^{\circ} \mathrm{C}\right)$. After two months there are discernable changes in $\mathrm{Mn}$ concentrations in solutions exposed to basaltic rocks at each temperature, whereas a discernable decrease in $\mathrm{Mg}$ concentrations take much longer. The combination of new discoveries, laboratory experiments, and manipulative in situ experiments will elucidate the significance of ridge flank hydrothermal systems on current and past geochemical cycles in the ocean. 